Original Research Paper

\title{
Setting Shrinkage Characteristics of Methyl Methacrylate- Modified Vinyl Ester Polymer Concrete
}

\author{
${ }^{1}$ Ki-Bong Choi, ${ }^{2}$ Seung-Ho Min and ${ }^{3}$ Kyu-Seok Yeon \\ ${ }^{I}$ Department of Architectural Engineering, Gachon University, Seongnam, South Korea \\ ${ }^{2}$ Building Projects Operation Division, GS E\&C, Seongnam, South Korea \\ ${ }^{3}$ Department of Regional Infrastructure Engineering, Kangwon National University, Chuncheon, South Korea
}

Article history

Received: 25-03-2016

Revised: $15-05-2016$

Accepted: 16-05-2016

Corresponding Author:

Kyu-Seok Yeon

Department of Regional

Infrastructure Engineering,

Kangwon National University,

Chuncheon, South Korea

$\mathrm{Ph}:+82-33-250-6465$

Email: ksyeon@kangwon.ac.kr

\begin{abstract}
This study evaluated the setting shrinkage characteristics of Methyl Methacrylate (MMA)-modified vinyl ester polymer concrete with different curing ages, MMA contents and curing temperatures. Results have shown that most of the setting shrinkage developed within $24 \mathrm{~h}$ after curing initiation. It was also found that an increase in MMA content led to an almost linear decrease in setting shrinkage, indicating that adding an MMA monomer was an effective measure to reduce the setting shrinkage of MMA-modified vinyl ester polymer concrete. A higher curing temperature tended to result in greater setting shrinkage, indicating that low-temperature curing is beneficial for reducing the setting shrinkage. The magnitude of setting shrinkage observed in vinyl ester polymer concrete was much greater than the drying shrinkage typically observed in ordinary Portland cement concrete but was smaller than the setting shrinkage of polymer concrete incorporating other types of binder.
\end{abstract}

Keywords: Polymer Concrete, MMA-Modified Vinyl Ester, Setting Shrinkage, MMA, Curing Temperature

\section{Introduction}

Polymer concrete is a particular type of concrete composed of inorganic aggregate and filler and organic polymeric binder. Polymer concrete is extensively used not only for repair of concrete roads and bridges but also manufacturing precast products such as manholes, sewage pipes and building walls due to its high strength, short setting time and excellent impact resistance, water resistance, corrosion resistance, freeze-thaw resistance and adhesiveness (Fowler, 1989). However, polymer concrete is relatively expensive and exhibits large deformations during setting and temperature changes. To resolve these issues, various studies including modification of binder characteristics and development of shrinkage-reducing agents and/or new resins have been actively conducted (Omata et al., 1995).

Unsaturated polyester resin, epoxy resin and acrylic resin are polymeric binders mainly used in polymer concrete, whose physical and mechanical properties significantly vary depending on the type of binder used. Among them, one of the most commonly used is unsaturated polyester resin due to its advantages in low price, easy-to-control setting time and high strength. In this study, vinyl ester resin was used for polymer concrete production not only has it good workability as in unsaturated polyester resin but also excellent physical and chemical properties as in epoxy resin. Also, it has superior heat performance and corrosion resistance and thus is widely used for new industrial applications such as coatings, printed circuit boards, metal foil laminates, building materials, automotive parts and fiber reinforced composites (Patel et al., 1990). Vinyl ester used in this study was modified using an Methyl Methacrylate (MMA) monomer (hereinafter "MMA-modified vinyl ester polymer concrete"). An MMA monomer has a low viscosity and thus is effective in controlling the viscosity of resin and reducing setting shrinkage, along with benefits in excellent chemical and corrosion resistance and high adhesiveness. It is anticipated that such advantages of vinyl ester resin and MMA monomer can lower binder's viscosity and, in turn, improve the physical and mechanical properties polymer concrete.

This study intended to examine the setting shrinkage characteristics of MMA-modified vinyl ester polymer concrete for different curing ages, MMA contents and curing temperatures since the setting shrinkage is an important element related to the adhesion property with 
substrate concrete when used as a repair material and the volume stability when used in precast products (Morgan, 1996; Ohama et al., 1987; Chandra and Ohama, 1994).

\section{Materials and Methods}

\section{Materials}

\section{Vinyl Ester Resin}

A vinyl ester resin was produced by the esterification of polyfunctional epoxy resin with unsaturated monocarboxylic acid (usually methacrylic or acrylic acid) in the presence of polymerization inhibiter, followed by the addition of polymerization diluent (usually styrene) (White and Hensen, 1991). The vinyl ester resin used in this study was a bisphenol a epoxy-based vinyl ester resin and its properties are shown in Table 1.

\section{MMA Monomer}

Methyl Methacrylate (MMA) is a colorless liquid, which was made by producing methacrylic acid through oxidization of $\mathrm{C} 4$ raffinate-extracted isobutylene at a gaseous state and then esterifying the methacrylic acid with methanol. Generally, MMA tends to have high stability, along with excellent transparency, climate resistance and colorability. Table 2 shows the properties of MMA used in this study.

\section{Initiator}

A DMP solution with 55\% Methyl Ethyl Ketone Peroxide (MEKPO) was used as an initiator for a vinyl ester resin. The properties of the initiator are shown in Table 3.

\section{Promotor}

Vinyl ester resin and MMA do not react with each other at a copolymerization state when only an initiator was added. Accordingly, to accommodate a quick reaction, a promotor is essentially required. In this study, cobalt naphthenate, which enables the polymerization at both room temperature and low temperature, was used as a promotor. The properties of the promotor are presented in Table 4.

\section{Aggregate and Filler}

If aggregate for polymer concrete absorbs water, water film formed on the aggregate's surface weakens the binder-aggregate adhesion and thus lowers the strength of polymer concrete. Thus, it is necessary to dry the aggregate before mixing to keep the water content less than $0.1 \%$ (Ohama, 1973). The physical properties and of the aggregate used in this study are shown in Table 5. This study used ground calcium carbonate as a filler because it is inexpensive and easily available. Also, it has good workability since it rarely absorbs polymer binders. The physical properties and chemical component of the filler used are shown in Table 6 and 7, respectively.

\section{Methods}

\section{Determination of Mixture Proportions}

Mixture proportions of polymer concrete vary depending on the type of polymer binder, shape and particle size of aggregate and working condition. The optimum mixture proportions can be achieved when maximizing the amount of aggregate, while minimizing the amount of polymer binder, as long as a certain degree of workability and strength is ensured. In this study, the optimum mixture proportions were determined by a series of preliminary experiments. The binder formations and mixture proportions for the polymer concrete used in this study are as shown in Table 8.

Table 1. Properties of vinyl ester resin

\begin{tabular}{llll}
\hline Density $\left(25^{\circ} \mathrm{C}\right)$ & Viscosity $\left(20^{\circ} \mathrm{C}, \mathrm{mPa} \cdot \mathrm{s}\right)$ & Vapor density & Styrene content $($ wt $\%)$ \\
\hline 1.2 & 250 & 3.6 & 45 \\
\hline
\end{tabular}

Table 2. Properties of MMA monomer

\begin{tabular}{llll}
\hline Density $\left(25^{\circ} \mathrm{C}\right)$ & Viscosity $\left(20^{\circ} \mathrm{C}, \mathrm{mPa} \cdot \mathrm{s}\right)$ & Molecular weight $(\mathrm{g} / \mathrm{mol})$ & Appearance \\
\hline 0.9420 & 0.56 & 100 & Transparent \\
\hline
\end{tabular}

Table 3. Properties of MEKPO

\begin{tabular}{lll}
\hline Component & Specific gravity $\left(25^{\circ} \mathrm{C}\right)$ & Active oxygen \\
\hline MEKPO 55\% DMP 45\% & 1.12 & 10.0 \\
\hline
\end{tabular}

Table 4. Properties of cobalt naphthenate

\begin{tabular}{lll}
\hline Density $\left(25^{\circ} \mathrm{C}\right)$ & Boiling point $\left({ }^{\circ} \mathrm{C}\right)$ & Appearance \\
\hline 0.95 & 110.6 & Violet liquid \\
\hline
\end{tabular}

Table 5. Physical properties of aggregate

\begin{tabular}{lllllll}
\hline Size $(\mathrm{mm})$ & Apparent density & Bulk density & Unit weight $\left(\mathrm{kg} / \mathrm{m}^{3}\right)$ & Fineness modulus & Water content $(\%)$ & Organic impurities \\
\hline $0.08-8$ & 2.64 & 2.62 & 1,648 & 3.09 & $<0.1$ & Nil \\
\hline
\end{tabular}


Table 6. Properties of ground calcium carbonate

\begin{tabular}{llllll}
\hline $\begin{array}{l}\text { Specific } \\
\text { gravity }(\mathrm{gr} / \mathrm{cc})\end{array}$ & $\begin{array}{l}\text { Absorption } \\
(\mathrm{cc} / \mathrm{gr})\end{array}$ & $\begin{array}{l}\text { Water } \\
\text { content }(\%)\end{array}$ & $\mathrm{pH}$ & $\begin{array}{l}\text { Mean grain } \\
\text { size }(\mu \mathrm{m})\end{array}$ & $\begin{array}{l}\text { Retained percentage } \\
\text { of } 325 \text { mesh sieve }\end{array}$ \\
\hline 0.75 & 0.20 & $\leqq 0.3$ & 8.8 & 13 & 0.03 \\
\hline
\end{tabular}

Table 7. Chemical component of ground calcium carbonate (unit: \%)

\begin{tabular}{llllll}
\hline $\mathrm{CaO}$ & $\mathrm{Al}_{2} \mathrm{O}_{3}$ & $\mathrm{Fe}_{2} \mathrm{O}_{3}$ & $\mathrm{SiO}_{2}$ & $\mathrm{MgO}$ & Loss on ignition \\
\hline 53.7 & 0.25 & 0.09 & 2.23 & 0.66 & 42.4 \\
\hline
\end{tabular}

Table 8. Binder formation and mix proportion of polymer concrete

\begin{tabular}{|c|c|c|c|c|c|}
\hline \multirow[b]{2}{*}{ Binder content ( $w t \%)$} & \multicolumn{5}{|l|}{ Binder formation } \\
\hline & VE: MMA (wt\%) & $\operatorname{MEKPO}\left(\mathrm{phr}^{*}\right)$ & Cobalt naphthenate (phr) & Filler (wt $\%)$ & Aggregate (wt $\%)$ \\
\hline$\overline{12.0}$ & 100: 0 & 2 & 2 & 18.00 & 70.00 \\
\hline 11.5 & $97.5: 2.5$ & & & 17.25 & 71.25 \\
\hline 11.0 & $95.0: 5.0$ & & & 16.50 & 72.50 \\
\hline
\end{tabular}

*parts per hundred parts of resin

\section{Setting Shrinkage Test}

Setting shrinkage developments in MMA-modified vinyl ester polymer concrete were measured as per the method proposed by Ohama et al. (1987) because this method is recognized to reasonably evaluate the linear shrinkage strains in hardening materials (Jensen and Hansen, 1995). The test setup consisted of two Linear Variable Differential Transformers (LVDTs) mounted at both ends of the mold. The size of the specimen was $70 \times 70 \times 320 \mathrm{~mm}$ and the test was conducted in an environmental chamber maintaining constant temperature and humidity conditions (test temperatures of $-10,0,10$ and $20^{\circ} \mathrm{C}$ and relative humidity of $60 \pm 3 \%$ ). Measured data were recorded using a data logger (Tokyosokki; TDS-602) with an interval of $10 \mathrm{~min}$ for the first $3 \mathrm{~h}$ and $30 \mathrm{~min}$ thereafter.

\section{Results}

\section{Setting Shrinkage Developments for Different Curing Ages}

Figure 1 shows the setting shrinkage developments of MMA-modified vinyl ester polymer concrete for the first $24 \mathrm{~h}$ of curing period; the period of setting shrinkage measurements was determined based on the results of a previous study (Ohama and Komiyama, 1979), in which the setting shrinkage of polyester resin concrete became almost constant at curing age of $24 \mathrm{~h}$. Also, test results for setting shrinkage for different curing temperatures, MMA contents and curing ages are summarized in Table 9. In the table, each value is the average of two measurements. The result shows that the setting shrinkage developments with respect to the ultimate setting shrinkage measured at $24 \mathrm{~h}$ were 0.06 to $76.71 \%$ at a curing age of $1 \mathrm{~h}$. At $3 \mathrm{~h}$, the rate of the setting shrinkage developments increased up to 74.9 to $95.7 \%$. This finding indicates that, except for the temperature level of $-10^{\circ} \mathrm{C}$, over $90 \%$ of the ultimate setting shrinkage occurred within the first $3 \mathrm{~h}$ after curing initiation. At a curing age of $6 \mathrm{~h}, 92.65$ to $98.26 \%$ of the ultimate setting shrinkage took place and the rate of setting shrinkage increase reached a nearly negligible level. The setting shrinkage measured was 0.02 to $30.33 \times 10^{-4}$ at $1 \mathrm{~h}, 25.87$ to $37.85 \times 10^{-4}$ at $3 \mathrm{~h}$ and 34.53 to $39.54 \times 10^{-4}$ at $24 \mathrm{~h}$ after curing initiation.

\section{Setting Shrinkage Developments for Different MMA Contents}

Figure 2 plots the effect of MMA content on the setting shrinkage development of MMA-modified vinyl ester polymer concrete. The result shows that an increase in MMA content led to an almost linear decrease in setting shrinkage regardless of the curing temperature. The measured setting shrinkage was found to be 35.85 to $39.54 \times 10^{-4}$ with 0 wt. $\%$ MMA, 34.94 to $38.68 \times 10^{-4}$ with 2.5 wt. $\%$ MMA and 34.53 to $37.66 \times 10^{-4}$ with 5 wt.\% MMA, indicating that the greater MMA content resulted in a reduction in setting shrinkage. The average setting shrinkage reduction rate with respect to the reference value (i.e., setting shrinkage with 0 wt.\% MMA) was found to be $2.3 \%$ when 2.5 wt.\% MMA was added and $4.3 \%$ when 5 wt. \% MMA was added. From the results, it can be concluded that the addition of MMA monomer was quite effective in reducing the setting shrinkage of MMA-modified vinyl ester polymer concrete.

\section{Setting Shrinkage Developments for Different Curing Temperatures}

Figure 3 illustrates the effect of curing temperature on the setting shrinkage of MMA-modified vinyl ester polymer concrete. The result revealed that an increase in curing temperature led to an almost linear increase in setting shrinkage. The measured setting shrinkage was 34.53 to $35.85 \times 10^{-4}$ at $-10^{\circ} \mathrm{C}, 34.69$ to $37.05 \times 10^{-4}$ at $0^{\circ} \mathrm{C}, \quad 35.90$ to $38.59 \times 10^{-4}$ at $10^{\circ} \mathrm{C}$ and 37.66 to $39.54 \times 10^{-4}$ at $20^{\circ} \mathrm{C}$, which implies that the higher curing temperature resulted in greater setting shrinkage. 




(a)

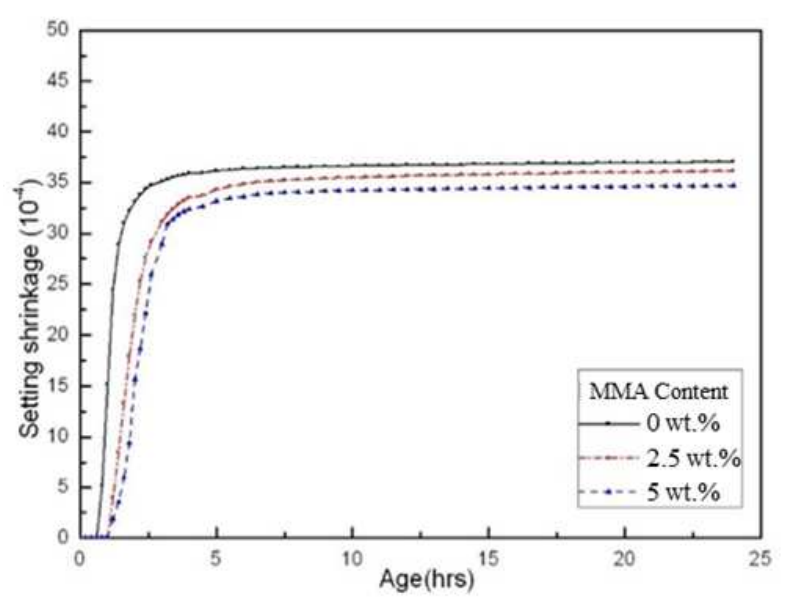

(c)



(b)

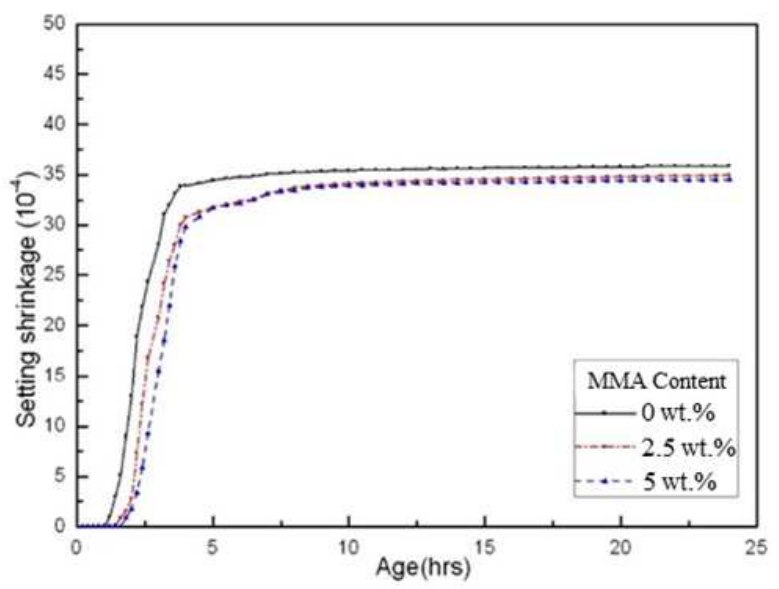

(d)

Fig. 1. Effect of curing temperature on setting shrinkage developments (a) $20^{\circ} \mathrm{C}$ (b) $10^{\circ} \mathrm{C}$, (c) $0^{\circ} \mathrm{C}$, (d) $-10^{\circ} \mathrm{C}$



Fig. 2. MMA content vs. setting shrinkage at age of $24 \mathrm{~h}$ 


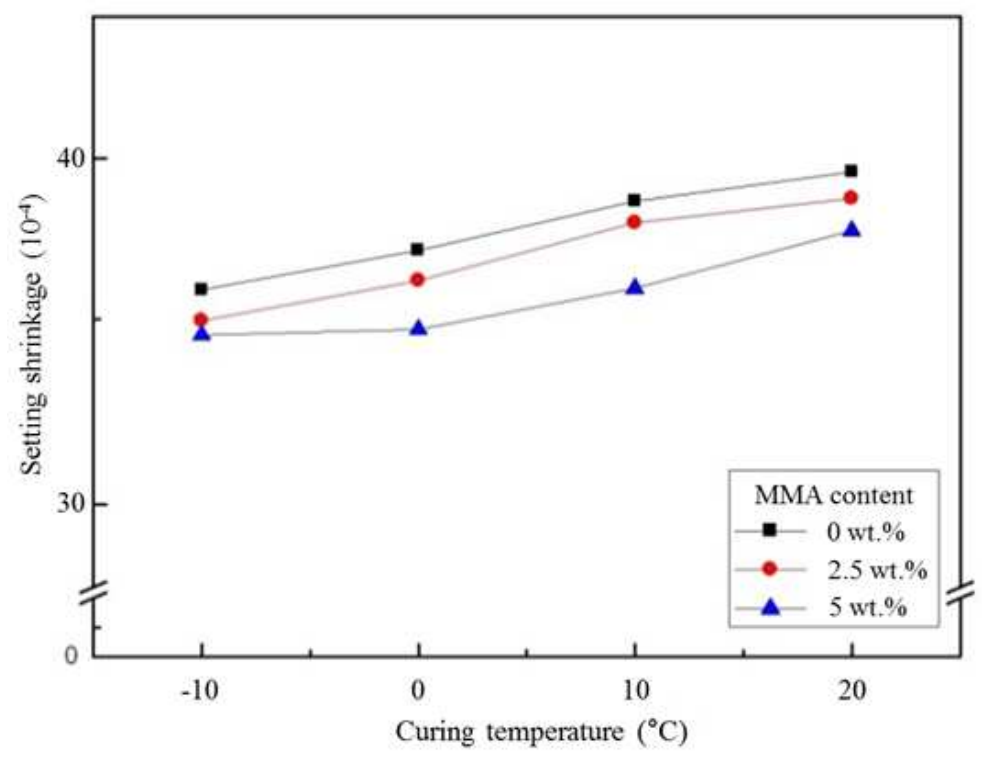

Fig. 3. Curing temperature vs. setting shrinkage at age of $24 \mathrm{~h}$

Table 9. Test results of setting shrinkage

\begin{tabular}{|c|c|c|c|c|c|c|}
\hline \multirow{2}{*}{$\begin{array}{l}\text { Curing } \\
\text { temperature }\left({ }^{\circ} \mathrm{C}\right)\end{array}$} & \multirow{2}{*}{$\begin{array}{l}\text { MMA } \\
\text { content (wt } \%)\end{array}$} & \multicolumn{5}{|c|}{ Setting shrinkage $\left(\times 10^{-4}\right)$} \\
\hline & & $1 \mathrm{~h}$ & $3 \mathrm{~h}$ & $6 \mathrm{~h}$ & $12 \mathrm{~h}$ & $24 \mathrm{~h}$ \\
\hline \multirow[t]{3}{*}{-10} & 0.0 & $0.07\left(0.20^{*}\right)$ & $33.15(92.47)$ & $34.78(97.02)$ & $35.52(99.01)$ & $35.85(100 \%)$ \\
\hline & 2.5 & $0.04(0.11)$ & $28.02(80.19)$ & $32.37(92.65)$ & $34.36(98.34)$ & $34.94(100 \%)$ \\
\hline & 5.0 & $0.02(0.06)$ & $25.87(74.92)$ & 32.18 (93.19) & $34.11(98.78)$ & $34.53(100 \%)$ \\
\hline \multirow[t]{3}{*}{0} & 0.0 & $15.19(41.00)$ & $35.65(96.22)$ & $36.35(98.11)$ & $36.72(99.11)$ & $37.05(100 \%)$ \\
\hline & 2.5 & $0.15(0.42)$ & $32.86(90.95)$ & $34.83(96.40)$ & 35.65 (98.67) & $36.13(100 \%)$ \\
\hline & 5.0 & $0.04(0.12)$ & $31.83(91.76)$ & $33.59(96.83)$ & $34.29(98.85)$ & $34.69(100 \%)$ \\
\hline \multirow[t]{3}{*}{10} & 0.0 & $24.16(62.61)$ & $37.38(96.86)$ & $37.92(98.26)$ & $38.25(99.12)$ & $38.59(100 \%)$ \\
\hline & 2.5 & $11.31(29.84)$ & $35.25(93.01)$ & $36.85(97.23)$ & $37.43(98.76)$ & $37.90(100 \%)$ \\
\hline & 5.0 & $4.00(11.14)$ & $33.56(93.48)$ & $35.13(97.86)$ & $35.55(99.03)$ & $35.90(100 \%)$ \\
\hline \multirow[t]{3}{*}{20} & 0.0 & $30.33(76.71)$ & $37.85(95.73)$ & $38.83(98.20)$ & $39.25(99.27)$ & $39.54(100 \%)$ \\
\hline & 2.5 & $11.21(28.98)$ & $36.71(94.91)$ & $37.87(97.91)$ & $38.30(99.02)$ & $38.68(100 \%)$ \\
\hline & 5.0 & $12.42(32.98)$ & $35.50(94.26)$ & $36.88(97.93)$ & $37.34(99.15)$ & $37.66(100 \%)$ \\
\hline
\end{tabular}

*Percentage of setting shrinkage development with respect to $24-\mathrm{hr}$ ultimate setting shrinkage

The average setting shrinkage increase rate was $1.9 \%$ between -10 and $0{ }^{\circ} \mathrm{C}, 3.7 \%$ between 0 and $10^{\circ} \mathrm{C}$ and $3.9 \%$ between 10 and $20^{\circ} \mathrm{C}$. This finding indicates that (1) the setting shrinkage increase rate increased as the curing temperature increased and (2) low-temperature curing is beneficial for minimizing the setting shrinkage of MMA-modified vinyl ester polymer concrete.

\section{Discussion of the Results}

There have been a number of research studies on the setting shrinkage of polymer concrete. Chandra and Ohama (1994) stated that the large setting shrinkage of polymer concrete is a problematic issue to be considered in the practical applications because the setting shrinkage typically reaches about five to ten times the drying shrinkage of Portland cement concrete, i.e., 50 to $60 \times 10^{-4}$. Ohama et al. (1987) stated that Polymethyl Methacrylate (PMMA) concrete had a large setting shrinkage of about $60 \times 10^{-4}$ and developed a method to reduce the setting shrinkage to nearly zero in the temperature range of -20 to $20^{\circ} \mathrm{C}$ using a shrinkagereducing agent. Yeon and Yeon (2012) found that the setting shrinkage of UP-MMA polymer concrete ranged from 29.2 to $82.6 \times 10^{-4}$, which was affected by UPMMA ratio, shrinkage-reducing agent content and curing temperature. Ohama and Komiyama (1979) discovered that the setting shrinkage of polyester resin concrete with a compressive strength of 70 to $80 \mathrm{MPa}$ was 40 to $50 \times 10^{-4}$. Also, they reported that the setting shrinkage can be reduced to an almost negligible level by incorporating a shrinkage-reducing agent. Also, Yeon et al. (2014) observed that the setting shrinkage 
of acrylic polymer concrete fell between 29.6 and $39.6 \times 10^{-4}$ and the magnitude increased as the MAA content increased because an increase in MAA content promotes the setting reactions.

In addition, many research efforts have been made to identify the drying shrinkage behavior of conventional Portland cement concrete. Neville (1996) described that there are various factors affecting the drying shrinkage of ordinary cement concrete. This study reported that the typical drying shrinkage after six months were 2 to $12 \times 10^{-4}$. Ngab et al. (1981) reported that high strength concrete with 60 -day compressive strength of 62 to 63 $\mathrm{MPa}$ experienced drying shrinkage of 3.4 to $4.3 \times 10^{-4}$. Huo et al. (2001) stated that high-performance concrete with compressive strength of 51 to $99 \mathrm{MPa}$ had the maximum drying shrinkage of 3.0 to $4.0 \times 10^{-4}$.

The MMA-modified vinyl ester polymer concrete investigated in this study showed the compressive strength of 64 to $70 \mathrm{MPa}$ and the setting shrinkage of 34.53 to $39.54 \times 10^{-4}$ at curing age of $24 \mathrm{~h}$. When compared with the previous studies, the setting shrinkage monitored in this study was much greater than the drying shrinkage of ordinary cement concrete but was less than the setting shrinkage of polymer concrete using binders other than vinyl ester resin. Rather, the setting shrinkage observed in this study was quite similar to that of acrylic polymer concrete $\left(29.6\right.$ to $\left.39.6 \times 10^{-4}\right)$, which is quite beneficial for ensuring volume stability and reducing cracking risk at early ages.

In this study, only setting shrinkage strain of MMAmodified vinyl ester polymer concrete was evaluated based on a laboratory test. Using the setting shrinkage data, along with materials' constitutive relationship, restraint condition and viscoelastic properties, stresses due to setting shrinkage could be achieved. The analysis of setting shrinkage stress requires further research.

\section{Conclusion}

Based on the experimental results obtained in this study, the following conclusions can be made:

- Results revealed that the setting shrinkage developments with respect to the ultimate setting shrinkage monitored at $24 \mathrm{~h}$ were 92.65 to $98.26 \%$ at $6 \mathrm{~h}$, indicating that most of the setting shrinkage in Methyl Methacrylate (MMA)-modified vinyl ester polymer concrete occurred within the first $6 \mathrm{~h}$ after curing initiation

- An increase in MMA content led to an almost linear decrease in setting shrinkage, regardless of the curing temperature. With addition of $5 \mathrm{wt} \% \mathrm{MMA}$, approximately a $4.3 \%$ decrease in setting shrinkage was observed. This finding implies that the addition of MMA monomer is an effective measure to reduce the setting shrinkage of MMA-modified vinyl ester polymer concrete

- As the curing temperature increased, the setting shrinkage increased almost linearly. This result indicates that low-temperature curing is effective for minimizing the setting shrinkage of MMA-modified vinyl ester polymer concrete

- When compared with the results of former studies, the setting shrinkage obtained in this study was much greater than the typical drying shrinkage of Portland cement concrete. However, it was less than the setting shrinkage of polymer concrete incorporating other binder types, which is beneficial for minimizing early-age cracking risk

\section{Acknowledgement}

The author would like to express their gratitude to National Research Foundation (NRF) of Korea and the research teams at Kangwon National University and Gachon University, South Korea for their support in performing this research.

\section{Funding Information}

This work was supported by National Research Foundation of Korea (NRF) grant funded by the Korea government (MSIP) (No. NRF-2013R1A1A2009). This study also supported by 2015 Research Grant from Kangwon National University (No. 520150126).

\section{Author's Contributions}

Ki-Bong Choi: Made substantial contributions to the experimental design, results discussions and final manuscript writing.

Seung-Ho Min: Performed the testing, data collection and data analysis.

Kyu-Seok Yeon: Managed the project as a principal investigator and drafted the manuscript.

\section{Ethics}

This article is original and unpublished elsewhere. The authors declare no conflict of interest in the development of the research and publication of this article.

\section{References}

Chandra, S. and Y. Ohama, 1994. Polymers in Concrete. 1st Edn., CRC Press, ISBN-10: 0849348153, pp: 204.

Fowler, D.W., 1989. Future trends in polymer concrete. Polymers Concrete: Adv. Applic., 116: 129-143.

Huo, X.S., N. Al-Omaisi and M.K. Tadros, 2001. Creep, shrinkage and modulus of elasticity of highperformance concrete. ACI Mater. J., 98: 440-449. 
Jensen, O.M. and P.F. Hansen, 1995. A dilatometer for measuring autogenous deformation in hardening Portland cement paste. Mater. Structures, 28: 406-409. DOI: $10.1007 / \mathrm{BF} 02473076$

Morgan, D.R., 1996. Compatibility of concrete repair materials and systems. Construct. Build. Mater., 10: 57-67. DOI: 10.1016/0950-0618(95)00060-7

Neville, A.M., 1996. Properties of Concrete. 4th Edn., John Wiley and Sons, Burnt Mill, ISBN-10: 0470235276, pp: 844 .

Ngab, A.S., A.H. Nilson and F.O. Slate, 1981. Shrinkage and creep of high strength concrete. ACI J., 78: 252-261.

Ohama, Y. and M. Komiyama, 1979. Early strength and length and change of polyester resin concrete with shrinkage-reducing agent. Proceedings of the 22nd Japan Congress on Materials ResearchMiscellaneous, (MRM' 79), pp: 356-359.

Ohama, Y., 1973. Mix Proportions and Properties of Polyester Resin Concretes. In: Polymers in Concrete, Chandra, S. and Y. Ohama (Ed.), CRC Press, ISBN-10: 0849348153, pp: 283-294.

Ohama, Y., K. Nawata and T. Kobayashi, 1987. Reduction in setting shrinkage of polymethyl methacrylate concrete. Proceedings of the 5th ICPIC, (PIC’ 87), pp: 179-1844.
Omata, F., M. Kawakami, S. Wakayama and H. Yamamura, 1995. Thermal stress and setting shrinkage stress of concrete members repaired by polymer mortar. Proceedings of the 8th ICPIC, (PIC' 95), Oostende, Belgium, pp: 113-118.

Patel, R.D., J.R. Thakkar, R.G. Patel and V.S. Patel, 1990. Glass-reinforced vinyl ester resin composites. High Perform. Polymers, 2: 261-265. DOI: $10.1177 / 095400839000200406$

White, M.N. and F.C. Hensen, 1991. Vinyl Ester Matrix Resins and Composites. In: International Encyclopedia of Composites, Lee, S.M. (Ed.), VCH, New York, ISBN-10: 0895737345.

Yeon, K.S. and J.H. Yeon, 2012. Setting shrinkage, coefficient of thermal expansion and elastic modulus of UP-MMA based polymer concrete. J. Korea Concrete Insti., 24: 491-498. DOI: 10.4334/JKCI.2012.24.4.491

Yeon, K.S., J.H. Yeon, Y.S Choi and S.H. Min, 2014. Deformation behavior of acrylic polymer concrete: Effects of methacrylic acid and curing temperature. Construct. Build. Mater., 63: 125-131. DOI: 10.1016/j.conbuildmat.2014.04.051 